\title{
18-Year-Old Woman with an Embryonal Rhabdo- myosarcoma of the Uterus in Statu Nascendi
}

\author{
18-jährige Patientin mit Erstdiagnose eines embryonalen \\ Rhabdomyosarkoms des Uterus in statu nascendi
}

Authors

Affiliations
O. Strahl ${ }^{1}$, A. Hartmann ${ }^{2,3}$, F. C. Thiel ${ }^{1}$, M. W. Beckmann ${ }^{1,3}$, M. P. Lux ${ }^{1}$

${ }^{1}$ FK-Erlangen, Erlangen

${ }^{2}$ Institute of Pathology, Friedrich-Alexander-Universitaet, Erlangen

${ }^{3}$ Comprehensive Cancer Center Erlangen-Nürnberg

\author{
Key words \\ - uterine tumor \\ - uterine sarcoma \\ - embryonal \\ rhabdomyosarcoma \\ - sarcoma botryoides \\ Schlüsselwörter \\ - Uterussarkom \\ - embryonales \\ Rhabdomyosarkom \\ - maligne Uterustumoren \\ - botryoides \\ Rhabdomyosarkom
}

$\begin{array}{ll}\text { received } & 21.11 .2012 \\ \text { revised } & 3.12 .2012 \\ \text { accepted } & 4.12 .2012\end{array}$

Bibliography

DOI http://dx.doi.org/

10.1055/s-0032-1328076

Geburtsh Frauenheilk 2012; 72:

1132-1136 @ Georg Thieme

Verlag KG Stuttgart · New York .

ISSN 0016-5751

\section{Correspondence}

Dr. Olga Strahl, Dr. med.

FK-Erlangen

Universitätsstraße 21-23

91054 Erlangen

olga.strahl@uk-erlangen.de

\section{Abstract \\ $\nabla$}

Background: We report a case of an 18-year-old woman with an embryonal rhabdomyosarcoma in statu nascendi.

Case: A fist-sized embryonal rhabdomyosarcoma of the uterus filling the vaginal vault was diagnosed in an adolescent with virgo intacta suffering from therapy resistant vaginal discharge, bleeding and bulging mass for six months. Further imaging revealed one suspicious pelvine lymph node. Excision of the tumour including the intracervical stalk was performed and followed by systemic multiagent chemotherapy. PET-CT scan presented a complete response after the third cycle. Histological complete response was shown by laparoscopic dissection of regional pelvic lymph nodes and curettage.

Conclusion: Uterine Rhabdomyosarcoma should be considered as differential diagnosis of therapy resistant vaginal flour and bleeding in young women. Fertility-sparing therapy is possible in selected exceptional cases.

\section{Introduction \\ $\nabla$}

Rhabdomyosarcomas (RMS) are malignant mesenchymal tumours originating from myogenic progenitor cells. They represent the most common soft tissue tumour in childhood but are rarely diagnosed in adults [1]. The head and neck region are the most affected tumour sites, fol-

\section{Zusammenfassung \\ $\nabla$}

Hintergrund: Wir berichten über eine 18-jährige Patientin mit Erstdiagnose eines embryonalen Rhabdomyosarkoms des Uterus in statu nascendi. Fallbericht: Bei einer 18-jährigen Patientin G0, virgo intacta fiel ein übelriechender, zerfallender Tumor im Bereich der Scheide auf. Die durchgeführte Biopsie zeigte einen malignen mesenchymalen Tumor mit Verdacht auf embryonales Rhabdomyosarkom. Bei starker vaginaler Blutung wurde am Aufnahmetag ein MRT des Beckens durchgeführt. Hier wurde ebenfalls der Verdacht auf ein Leiomyosarkom ausgehend von der Vagina mit Zervixbeteiligung und zusätzlich eines metastasensuspekten Lymphknoten rechts pelvin diagnostiziert. Nach vaginaler Partialexzision des Primarius wurde mit systemischer Chemotherapie begonnen. Die Reevaluation mittels PET-CT nach dem 3. Zyklus der systemischen Therapie zeigte eine ycT0-ycNO-cMO-Situation. Die Komplettremission konnte durch laparoskopisch durchgeführte pelvine Lymphnodektomie rechts und fraktionierte Kürettage histologisch bestätigt werden.

Fazit: Bei den jungen Patientinnen mit therapieresistenten vaginalen Fluor und Blutungen sollte bei der Differenzialdiagnose an ein uterines Rhabdomyosarkom gedacht werden. In Ausnahmefällen kann die Tumortherapie auch fertilitätserhaltend durchgeführt werden.

lowed by the genitourinary tract $[1,2]$. Approximately $3 \%$ of rhabdomyosarcomas in adults originate in the female genitals [2]. Three major histological subtypes can be differentiated according to the Intergroup Rhabdomyosarcoma Study Group (IRSG) and the WHO classification: the embryonal (including botryoides as most frequent variant [3]), the alveolar and the pleomorphic/un- 


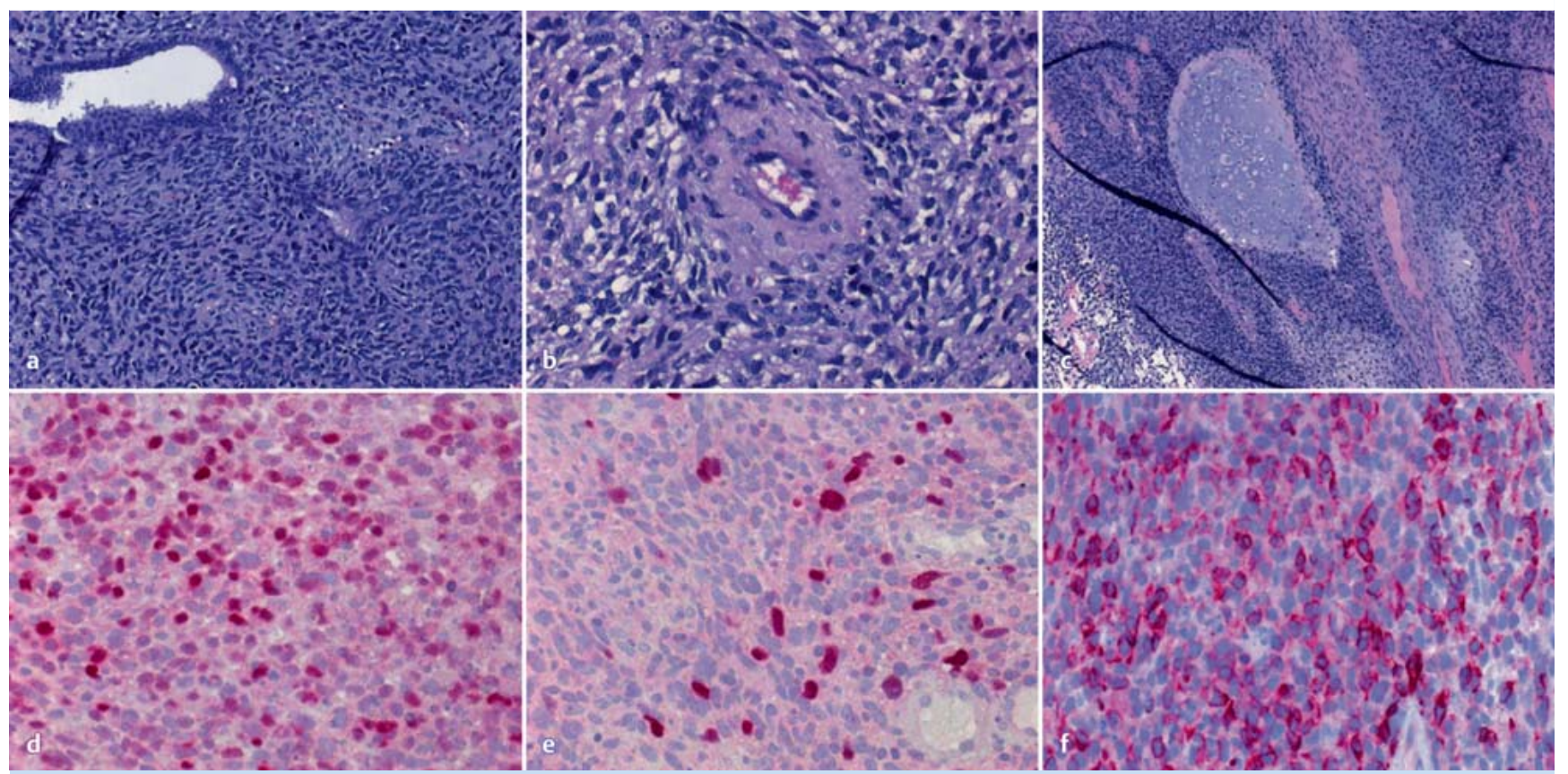

Fig. 1 a to $\mathbf{f}$ a-c Histopathological examination. $\mathbf{d}-\mathbf{f}$ Immunhistochemical staining: $\mathbf{d}$ MyoD1; e myogenin; $\mathbf{f}$ desmin.

differentiated type. The majority of RMSs originating from the female genital tract are embryonal and botryoid types.

The botryoid type has a typical "grape-like" appearance due to a layer of spindle cells pushing up beneath the mucosa in polypoid masses. It is usually found in the infantile vagina but can also occur in the cervix. Cervical RMS is usually seen in the second decade of life. Because skeletal muscle is not normally found in the genital tract, RMS is a heterologous tumor. The mean age at diagnosis of patients suffering from embryonal RMS arising in the cervix is higher than that of patients with vaginal lesions $[4,5]$. The clear differentiation of histological subtypes is important due to significant discrepancy in clinical behaviour and prognosis. Especially embryonal RMS of the uterus is suggested to represent an extreme rare and aggressive form associated with poor prognosis [1,2,6-8].

Survival management has changed significantly over the past 20 years. Hilgers et al. in 1970 recommended that vaginal RMS was best treated by pelvic exenteration [9]. The addition of adjuvant chemotherapy makes a substantial contribution to the improvement in survival [10]. The preoperative chemotherapy with or without radiotherapy can allow preservation of the bladder and rectum $[11,12]$, and even save the uterus for fertility with wide local excision of cervix $[13,14]$.

Unfortunately, no standard therapy regimen is established for treatment of RMS in adults. Treatment is carried out according to the guideline for treatment in childhood in most adult cases. It usually includes surgery, multiagent chemotherapy (vincristine, cyclophosphamide, Adriamycin) and radiotherapy.

Up to now, 16 cases of uterine RMS in adults have been reported whereas no case appeared in association with a tumour of the uterus in statu nascendi [2].

\section{Case}

\section{$\nabla$}

Suffering from therapy resistant vaginal discharge and bleeding for 6 months an 18-year-old woman (virgo intacta) was treated with antibiotic and antifungal drugs by her gynaecologist. No improvement was notable. The first physical examination revealed a tumour filling out the vagina. A small biopsy was performed and there was strong suspicion for a malignant mesenchymal tumour without definitive diagnosis due to limited material. Therefore the patient was referred to our centre.

Physical examination was not possible. Vulvar examination was extremely painful and presented a fist-sized, bleeding tumour of the uterus in statu nascendi without signs of an infection.

Subsequently we performed an examination during anesthesia and vaginal surgery. The tumour and the stalk passing the cervical canal were removed. There were no pathological findings in the parametric areas and the vagina. Histopathological examination confirmed an embryonal rhabdomyosarcoma ( $\bullet$ Fig. 1).

The tumour was homogeneous with spindle and polygonal cells and scattered multinucleated giant cells with polymorphic and hyperchromatic nuclei and perivascular growth ( $\nabla$ Fig. 1 a-c). There was no clear rhabdomyogenic differentiation or rhabdomyoblasts. There were disseminated necrosis, focal chondroid differentiation and a very high proliferation with 8 mitosis in one high-power field and a proliferation of $80 \%$ in Ki-67 immunohistochemistry. Immunohistochemical work-up showed that the tumor was strongly expressing Desmin and MyoD1 in 50$60 \%$ and Myogenin in 20\% of tumor cells ( Fig. 1d-f). Epithelial markers (CK, EMA), smooth muscle markers (smooth muscle actin, h-caldesmon), neurogenic markers to exclude a malignant neurogenic sarcoma with rhabdomyoblastic differentiation or malignant Triton tumour (S100) and PAX5 were all negative.

The tumour was classified as grade III (high grade) according to the FNCLCC grading system with an overall score of 7. 

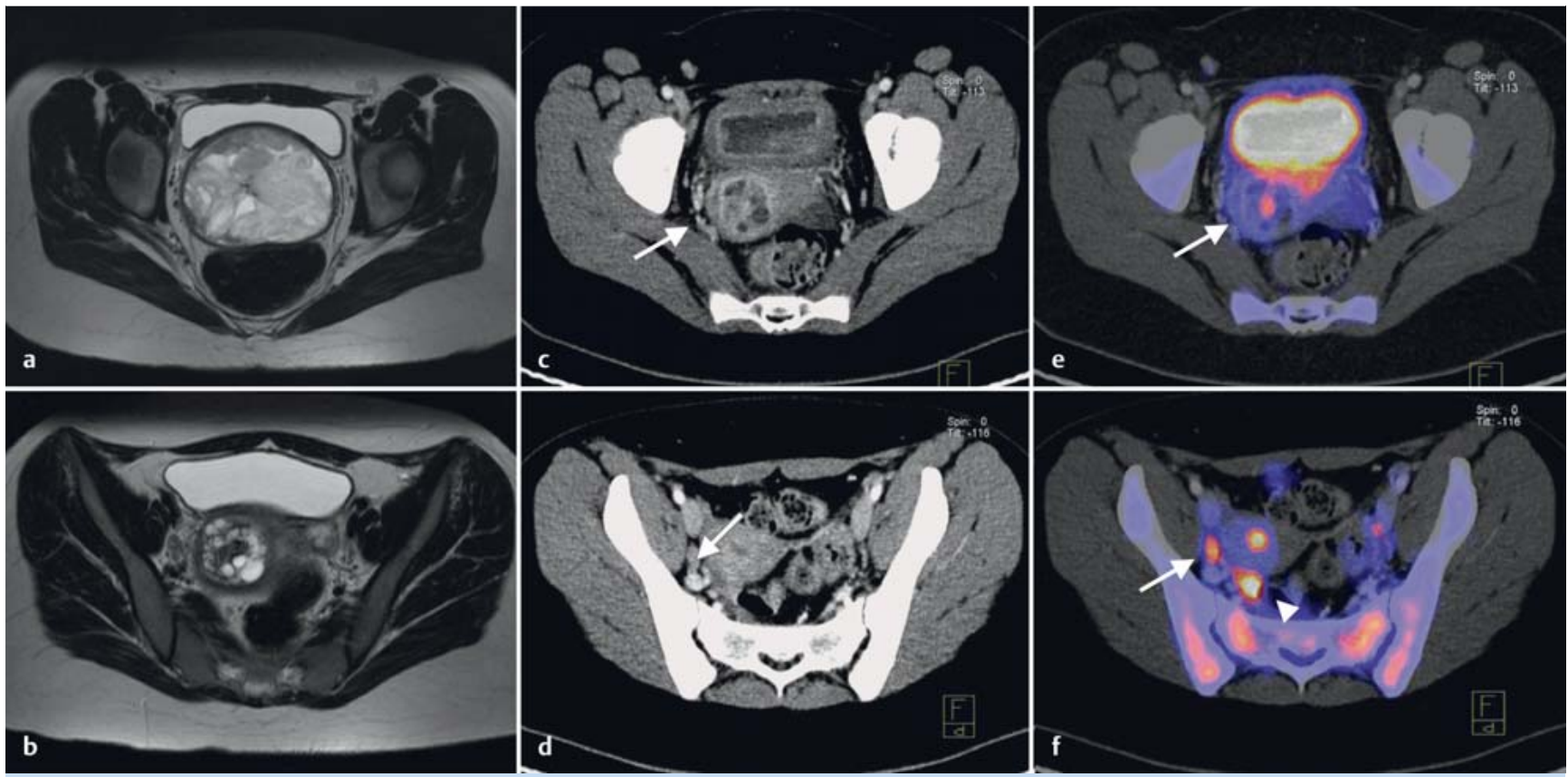

Fig. $\mathbf{2} \mathbf{a}$ to $\mathbf{f}$ a, $\mathbf{b}$ MRI T2w before surgery: $\mathbf{a}$ intravaginal part of the tumour; b cavum uteri including tumour stalk. c-f $18 \mathrm{~F}-\mathrm{FDG}-\mathrm{PET} / \mathrm{CT}$ (after sur-

gery): c, e residual tumour (arrow); d, f suspicious lymph node (arrow) and stimulated ovary (arrow head).

The staging of patients with a rhabdomyosarcoma is relatively complex. The process includes the following steps [15]:

- assigning a stage (consider site, size, surgico-pathologic group, and presence/absence of metastases),

- assigning a local tumor surgico-pathologic group (status postsurgical resection/biopsy, with pathologic assessment of the tumour margins), and

- assigning a risk group (classified by stage, group, and histology).

Postoperative imaging by PET/CT scan presented a tumour rest in the uterine cavity and one suspicious lymph node in the right pelvic area ( Fig. 2) There was no further distant disease. According to the IRS Clinical grouping Classification the diagnosis was a group IIB embryonal rhabdomyosarcoma of the uterus. Risk stratification corresponding to the CWS guidance (dependent on IRSG age, node status, metastasis and site) presented a high risk group and subgroup [15].

Therefore, a multiagent chemotherapy with ifosfamide (3000 mg/m²), d $1+2$, vincristine $\left(1.5 \mathrm{mg} / \mathrm{m}^{2}\right), \mathrm{d} 1+8+15$, courses 1 and $2+\mathrm{d} 1$ of courses $3+4$, and actinomycin $\mathrm{D}\left(1.5 \mathrm{mg} / \mathrm{m}^{2}\right), \mathrm{d} 1$, q21d, was recommended and started according to the CWS guidance. A cryoconservation of ovarian tissue was performed before chemotherapy. After the initial three courses of chemotherapy a re-staging by PET/CT scan was done which revealed a complete response. Consequently another cycle of chemotherapy was given for consolidation.

Afterwards, secondary surgery was performed including laparoscopic dissection of regional pelvic lymph nodes and endometrial and endocervical curettage. No residual tumour was diagnosed intraoperatively ( Fig.3). Histopathological examination confirmed the complete response. Due to lack of evidence based on guidelines for aftercare, follow-up visits were arranged every three months including gynaecological ultrasound, complete CT scan every six months and a nuclear bone scans every 12 months since July 2010. The patient started to menstruate again 5 months after the last cycle of chemotherapy. The last follow-up examination, which was performed in April 2012, revealed no abnormal findings ( $\odot$ Fig. 4).

\section{Comment}

RMS is a common soft tissue tumour in childhood but is rarely seen in adults. The most common tumour site is usually the neck and head region, followed by the genitourinary tract. Cervix and uterus are the most frequently affected tumour sites in adolescent and postmenopausal women with tumours arising in the genitourinary tract, respectively. RMS often occurs as an extremely heterologous tumour, because skeletal muscles are naturally not found in the female genitals [16]. According to the histological examination three different subtypes of RMS can be classified: the embryonal, the alveolar and the pleomorphic subtypes. Main differential diagnoses are leiomyosarcoma, adenosarcoma, carcinomasarcoma and malignant neurogenic sarcoma with rhabdomyoblastic differentiation (malignant Triton tumour) [1]. Therefore, histological findings like neoplastic pleomorphic skeletal muscle cells of varying differentiation, sometimes with myxoid stroma or cartilage diffentiation, have to be confirmed by immunhistochemical staining with myogenin, desmin and MyoD1 ( Fig. 1) $[1,2,6,15]$. Furthermore any epithelial differentiation has to be excluded by extensive sampling of the tumour and immunohistochemistry.

The treatment of patients with RMS is a multimodality challenge. Therapy strategy includes systemic chemotherapy, in combination with either surgery, radiation therapy (RT), or both modalities for local tumour control. Surgical resection should be performed, if feasible without major functional/cosmetic impairment, followed by chemotherapy and RT. Some patients with initially unresected tumours may undergo second-look surgery to 

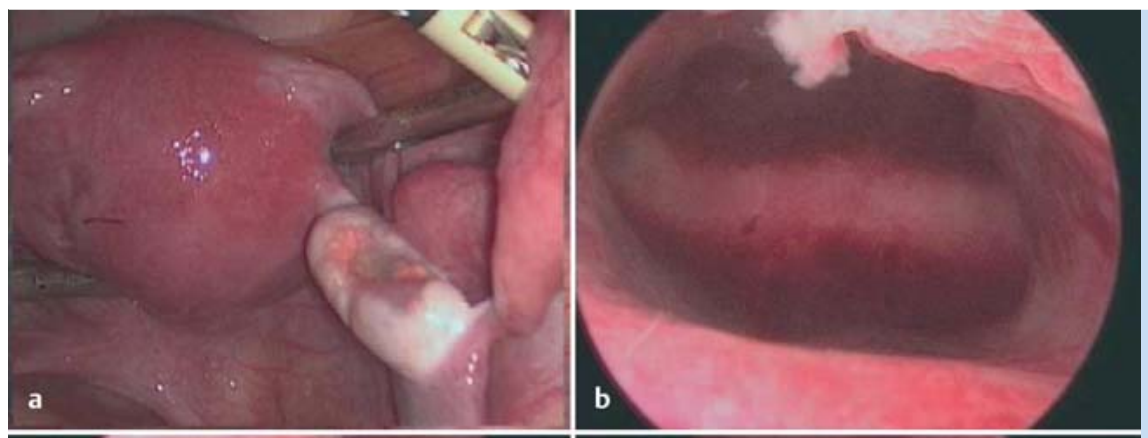

Fig. 3 a to $\mathbf{d}$ Intraoperative pictures final surgery after cycle 4.

a Fundus uteri: Laparoscopic view from abdominal; b fundus uteri: hysteroscopic view cavum uteri; c, d ostium of fallopian tubes bilateral: hysteroscopic view cavum uteri.
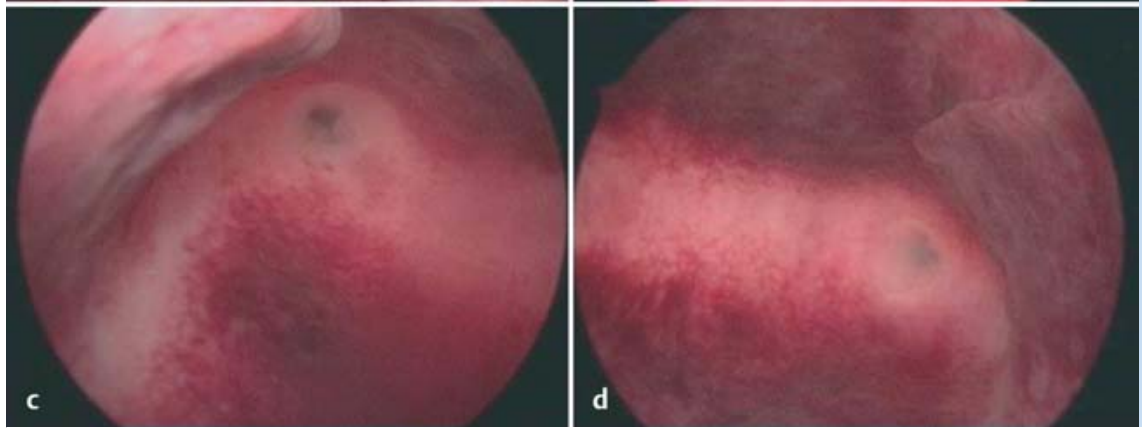

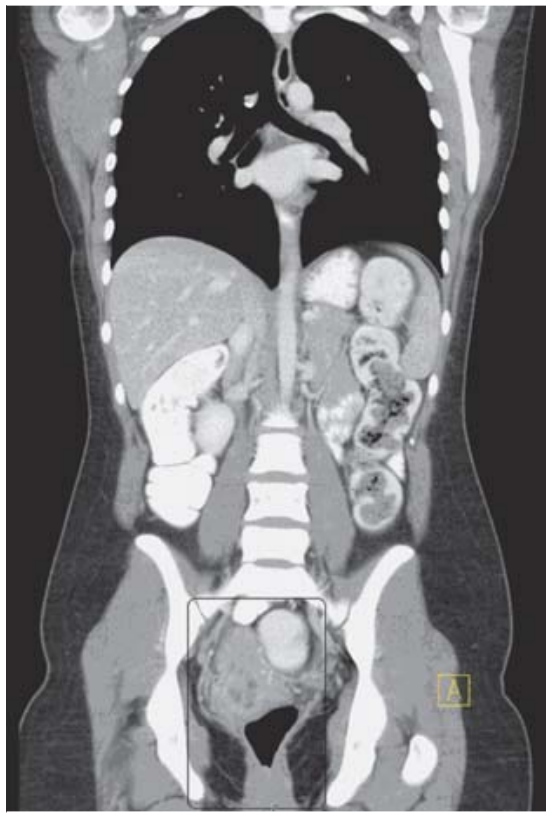

Fig. 4 CT thorax/ abdomen (2012-04-10). No organ or lymph node metastases.

remove the residual tumour. Because RMS is sensitive to chemotherapy and RT, surgery is delayed if disfigurement or interference with organ function is probable.

RT is indicated for patients with microscopic residual (Group II) disease, gross residual (Group III) disease or Group I patients with alveolar histology. The discussion of treatment options for children with RMS is therefore divided into separate sections describing surgery, chemotherapy, and RT [17]. In most cases fertility-sparing surgery is impossible and usually hysterectomy, bilateral adnexectomy and dissection of regional lymph nodes are performed.

Some authors suggested that embryonal RMS in adults have a poor prognosis, irrespective of the selected therapy, whereas others reported an improved survival comparable to the survival rates in childhood $[2,18]$. Due to lack of prospective randomized studies it is difficult to specify the individual prognosis.

We report a case of an 18-year-old patient (virgo intacta) suffering from a fist-sized embryonal RMS of the uterus in statu nascendi. Because the main tumour mass was located in the vagina (being in statu nascendi) it could easily be removed during the first examination in anaesthesia. Regarding the suspect pelvine lymph node a multiagent chemotherapy was performed according to the CWS guidance and secondary surgery was performed afterwards. Re-staging visualized a complete response enabling a fertility-sparing surgery which was favoured by the patient and her family. Up to now, follow-up examinations showed no signs for distant metastasis or local recurrence.

To our knowledge, fertility-sparing surgery is not described for uterine embryonal RMS up to now. Kayton et al. [18] reported a case of an anaplastic embryonal RMS involving the cervix uteri in a 12-year-old girl. They performed a fertility-sparing surgery with radical abdominal trachelectomy for local control and to avoid infertility. Subsequently adjuvant multiagent chemotherapy was given. No local recurrence was diagnosed up to the date of publication.

Similarly, a case of a 19-year-old woman suffering from a botryoid RMS of the posterior lip of the cervix was described by Bernal et al. [19]. The RMS was located to the vagina and was removed including the cervical part by curettage. Postoperative imaging showed no evidence of distant disease. Secondary surgery was carried out by conisation. No residual tumour was identified in histological analysis. Adjuvant multiagent chemotherapy was given and no evidence of disease was seen after a follow-up of 11 months.

A case of embryonal RMS of the uterus was described in a 15year-old adolescent by da Silva et al. [2]. The tumour was expelling through the cervix into the vagina comparable to the present case, but also with inversio uteri. Origin of the tumour was the fundus uteri. The reason for the inversion was thought to be the softening of the uterine wall caused by the rapidly growing tumour. Uterus-conserving surgery was no reasonable option for 
local tumour control although the tumour was classified as Group I tumour according to the IRSG Grouping classification. In the present case no inversio uteri was noticeable. The tumour did not affect the uterine wall but expelled directly through the cervix into the vagina. Therefore resection of the tumour with the stalk was possible and only a very small tumour rest was remaining in situ. This was treated with combined chemotherapy. In conclusion, embryonal RMS of the uterus is a rare neoplasia in adult women. A poor prognosis is described in literature. Main symptoms are therapy resistant bleeding and discharge. The histopathological diagnosis has to be confirmed by extensive tumour sampling to exclude a carcinosarcoma and immunohistochemical 1 staining for MyoD1, desmin and myogenin. Therapy usually includes fertility-compromising surgery, multiagent chemotherapy and radiotherapy. Fertility-sparing surgery is described to be possible in exceptional cases of RMS of the cervix. The present case shows that in individual cases fertility-sparing surgery is possible for young patients suffering from RMS of the uterus. Further studies are necessary to evaluate the most effective treatments for adult patients.

\section{Conflict of Interest}

None.

\section{References}

1 Ferguson SE, Gerald W, Barakat RR et al. Clinicopathologic features of rhabdomyosarcoma of gynecologic origin in adults. Am J Surg Pathol 2007; 31: 382-389

2 da Silva BB, Dos Santos AR, Bosco Parentes-Vieira J et al. Embryonal rhabdomyosarcoma of the uterus associated with uterine inversion in an adolescent: a case report and published work review. J Obstet Gynaecol Res 2008; 34 (4 Pt 2): 735-738

3 Perrone T, Carson LF, Dehner LP. Rhabdomyosarcoma with heterologous cartilage of the uterine cervixa clinicopathologic and immunohistochemical study of an aggressive neoplasm in a young female. Med Pediatr Oncol 1990; 18: 72-76

4 Copeland LJ, Sneige N, Stringer A et al. Alveolar rhabdomyosarcoma of the female genitalia. Cancer 1985; 56: 849-855
5 Montag TWD, Ablaing G, Schlaerth JB et al. Embryonal rhabdomyosarcoma of the uterine corpus and cervix. Gynecol Oncol 1986; 25: 171-194

6 Zeisler H, Mayerhofer K, Joura EA et al. Embryonal rhabdomyosarcoma of the uterine cervix: case report and review of the literature. Gynecol Oncol 1998; 69: 78-83

7 Brand E, Berek JS, Nieberg RK et al. Rhabdomyosarcoma of the uterine cervix. Sarcoma botryoides. Cancer 1987; 60: 1552-1560

8 Scaravilli G, Simeone S, Dell'Aversana Orabona G et al. Case report of a sarcoma botryoides of the uterine cervix in fertile age and literature review. Arch Gynecol Obstet 2009; 280: 863-866

9 Hilgers RD, Malkasian GD, Soule EH. Embryonal rhabdomyosarcoma (botryoid type) of the vaginaa clinicopathologic review. Am J Obstet Gynecol 1970; 107: 484-502

10 Heyn RM, Holland R, Newton jr. WA et al. The role of combined chemotherapy in the treatment of rhabdomyosarcoma in children. Cancer 1974; 634: 2128-2142

11 Kumar APM, Wern EL, Fleming ID et al. Combined therapy to prevent complete exenteration for rhabdomyosarcoma of the vagina or uterus. Cancer 1976; 37: 118-122

12 Copeland LJ, Gershenson DM, Saul PB et al. Sarcoma botryoides of the female genital tract. Obstet Gynecol 1985; 66: 262-266

13 Gordon AN, Montag TW. Sarcoma botryoides of the cervix: excision followed by adjuvant chemotherapy for preservation of reproductive function. Gynecol Oncol 1990; 36: 119-124

14 Daya DA, Scully RE. Sarcoma botryoides of the uterine cervix in young women: a clinicopathological study of 13 cases. Gynecol Oncol 1988; 29: 290-304

15 Cooperative Weichteilsarkom Study Group CWS der GPOH in cooperation with the European paediatric Soft Tissue Sarcoma Study Group. EpSSG CWS-guidance for risk adapted treatment of soft tissue sarcoma and soft tissue tumours in children, adolescents, and young adults. Version 1.5. from 1.7.2009, http://www.kinderkrebsinfo.de/e9031/ e10591/e77084/e110986/index_ger.html

16 Behtash N, Mousavi A, Tehranian A et al. Embryonal rhabdomyosarcoma of the uterine cervix: case report and review of the literature. Gynecol Oncol 2003; 91: 452-455

17 Donaldson SS, Meza J, Breneman JC et al. Results from the IRS-IV randomized trial of hyperfractionated radiotherapy in children with rhabdomyosarcoma-a report from the IRSG. Int J Radiat Oncol Biol Phys 2001; 51: 718-728

18 Kayton ML, Wexler LH, Lewin SN et al. Pediatric radical abdominal trachelectomy for anaplastic embryonal rhabdomyosarcoma of the uterine cervix: an alternative to radical hysterectomy. J Pediatr Surg 2009; 44: 862-867

19 Bernal KL, Fahmy L, Remmenga S et al. Embryonal rhabdomyosarcoma (sarcoma botryoides) of the cervix presenting as a cervical polyp treated with fertility-sparing surgery and adjuvant chemotherapy. Gynecol Oncol 2004; 95: 243-246 